\title{
Numerical Simulation of the Wind Action on a Long-Span Bridge Deck
}

\author{
A. L. Braun \\ PPGEC/UFRGS \\ Av. Osvaldo Aranha, 99 - 30 andar \\ 90035-190 Porto Alegre, RS. Brazil \\ www.cpgec.ufrgs.br \\ allbraun@ig.com.br

\section{A. M. Awruch} \\ PPGEC/UFRGS \& PROMEC/UFRGS \\ Av. Sarmento Leite, 425 \\ 90050-170 Porto Alegre, RS. Brazil \\ www.mecanica.ufrgs.br/promec \\ awruch@adufrgs.ufrgs.br
}

A numerical model to study the aerodynamic and aeroelastic bridge deck behavior is presented in this paper. The flow around a rigid fixed bridge cross-section, as well as the flow around the same cross-section with torsional motion, are investigated to obtain the aerodynamic coefficients, the Strouhal number and to determine the critical wind speed originating dynamic instability due to flutter. The two-dimensional flow is analyzed employing the pseudo-compressibility approach, with an Arbitrary Lagrangean-Eulerian (ALE) formulation and an explicit two-step Taylor-Galerkin method. The finite element method (FEM) is used for spatial discretization. The structure is considered as a rigid body with elastic restrains for the cross-section rotation and displacement components. The fluid-structure interaction is accomplished applying the compatibility and equilibrium conditions at the fluid-solid interface. The structural dynamic analysis is performed using the classical Newmark's method.

Keywords: Fluid-structure interaction, Finite Element Method (FEM), Large Eddy Simulation (LES), aeroelasticity, aerodynamics

\section{Introduction}

Wind tunnel tests for assessment of aerodynamic and aeroelastic informations in the study of bridge girders performance are numerically simulated in this work. The usual way to obtain these informations is using representative models in a wind tunnel. However, with the improvement in computers technology and computational fluid dynamics ( $C F D$ ) algorithms, many of these problems can also be analyzed by numerical simulation.

Long-span bridges, such as suspension bridges for example, must be designed to support, from a static point of view, the mean wind forces (using the drag, lift and pitching moment coefficients). Besides, considering that such structures show low damping and low stiffness, they are subjected to aeroelastic phenomena, such as flutter, galloping and vortex shedding induced vibrations. Only the first case will be studied in the present work.

The term aeroelasticity is used when the aerodynamic forces produce some kind of structural instability as a consequence of the interaction between these forces and the structural motion. The flutter phenomenon is a type of aeroelastic instability that begins when the effective damping (structural + aerodynamic) becomes negative.

Kawahara \& Hirano (1983) were one of the first authors to analyze numerically the wind action on a bridge cross-section. They used the Finite Element Method (FEM) to obtain the aerodynamic coefficients as functions of the angle of attack of the wind and the Strouhal number. Kuroda (1997) employed two different numerical procedures to study the approaching span of the Great Belt East Bridge: the Finite Element Method and the Finite Difference Method $(F D M)$, and Large Eddy Simulation (LES) with the Smagorinsky's model for the turbulent flow. He also presented the results referring to the aerodynamic coefficients for various angles of attack and the Strouhal number for both numerical methods employed in his analysis. Larsen \& Walther (1997) analyzed several bridge decks observing their aeroelastic behaviour using a numerical code based on Discrete Vortex Simulation (DVS), presenting the respective critical flutter velocity (using the flutter derivatives). Recently, Selvam et al. (2002) applied a direct method for the flutter analysis. They used (FEM) and (LES).

In this work, the analysis of the flow of a slightly compressible fluid in a two-dimensional flow domain was carried out using an

Paper accepted August, 2003. Technical Editor: Aristeu da Silveira Neto.. explicit two-step Taylor-Galerkin method with an Arbitrary Lagrangean-Eulerian $(A L E)$ description. A similar Taylor-Galerkin formulation was used by Tabarrok \& Su (1994) and by Rossa \& Awruch (2001), but with a semi-implicit scheme. The (ALE) scheme was first presented by Hirt et al. (1974) in a numerical work. Since this first paper many other authors used this description with the same concepts. The classical Smagorinsky's model, similar to that presented by Kuroda (1997), was employed for the sub-grid scales simulation. The finite element method was used for spatial discretization. The structure was considered as a rigid body with elastic restrains for the cross-section rotation and displacement components. The coupling between fluid and structure was performed applying the compatibility and equilibrium equations at the interface. The structural dynamic analysis was accomplished using the classical Newmark's method (Bathe, 1996). Examples are presented to illustrate the capability of the computational method.

\section{Governing Equations for the Flow Simulation}

The governing equations, considering the pseudocompressibility approach in an isothermic process, Large Eddy Simulation (LES) with Smagorinsky's model for turbulent flows and an Arbitrary Lagrangean-Eulerian $(A L E)$ description, are:

a) Momentum equations:

$\frac{\partial v_{i}}{\partial t}+\left(v_{j}-w_{j}\right) \frac{\partial v_{i}}{\partial x_{j}}+\frac{1}{\rho} \frac{\partial p}{\partial x_{j}} \delta_{i j}-\frac{\partial}{\partial x_{j}}\left[\left(v+v_{t}\right)\left(\frac{\partial v_{j}}{\partial x_{i}}+\frac{\partial v_{i}}{\partial x_{j}}\right)+\lambda \frac{\partial v_{k}}{\partial x_{k}} \delta_{i j}\right]=0$
$(\mathrm{i}, \mathrm{j}, \mathrm{k}=1,2)$ in $\grave{U}$

being $\quad v_{t}=\left(C_{S} \Delta\right)^{2}\left(2 S_{i j} S_{i j}\right)^{1 / 2} \quad$ with $\quad S_{i j}=\frac{1}{2}\left(\frac{\partial v_{i}}{\partial x_{j}}+\frac{\partial v_{j}}{\partial x_{i}}\right) \quad$ and $\ddot{A}=\left(\ddot{A}_{x} \ddot{A}_{y}\right)^{1 / 2}$, where $\ddot{A}_{x}$ and $\ddot{A}_{y}$ are the element dimensions in the global axis direction $x$ and $y$, respectively.

b) Mass conservation equation:

$$
\frac{\partial p}{\partial t}+\left(v_{j}-w_{j}\right) \frac{\partial p}{\partial x_{j}}+\rho c^{2} \frac{\partial v_{j}}{\partial x_{j}}=0 \quad(\mathrm{j}=1,2) \text { in } \grave{U}
$$

which is obtained considering $\partial p / \partial \rho=c^{2}$.

The boundary conditions of Eqs. (1) and (2) are the following: 
$v_{i}=w_{i}(\mathrm{i}=1,2)$ on the solid boundary $\tilde{A}_{v_{S}}$

$\boldsymbol{v}=\hat{\boldsymbol{v}}$ on the boundary $\tilde{A}_{v_{a}}$ or

$p=\hat{p}$ on the boundary $\tilde{A}_{p}$

$$
\begin{aligned}
& {\left[\frac{-p}{\tilde{n}} \ddot{a}_{i j}+\left(i+i_{t}\right)\left(\frac{\partial v_{i}}{\partial x_{j}}+\frac{\partial v_{j}}{\partial x_{i}}\right)+\ddot{e} \frac{\partial v_{k}}{\partial x_{k}}\right] n_{j}=\frac{\dot{o}_{i j} n_{j}}{\tilde{n}}=S_{i}} \\
& (\mathrm{i}, \mathrm{j}, \mathrm{k}=1,2) \text { in } \tilde{A}_{\dot{o}}
\end{aligned}
$$

In these equations, $v_{i}$ and $p$ (the velocity components and the pressure, respectively) are the unknowns. The viscosities $i=i / \tilde{n}$ and $\ddot{e}=\dot{\doteqdot} / \tilde{n}$, the specific mass $\tilde{n}$ and the sound velocity $c$, are the fluid properties. The eddy viscosity $i_{t}={ }^{i} t / \tilde{n}$ depends of derivatives of the filtered velocity components, of the element dimensions and of the Smagorinsky's constant $C_{S}$. For a purely Eulerian description, the mesh motion velocity $\boldsymbol{w}$ at each nodal point, with components $w_{i}$, is equal to zero. Now, for a purely Lagrangean description, the mesh motion velocity at each nodal point is equal to the fluid velocity, i.e. $v_{i}=w_{i}(\mathrm{i}=1,2)$. Finally, in an Arbitrary Lagrangean-Eulerian formulation, $\boldsymbol{w} \neq 0$ and $\boldsymbol{w} \neq \boldsymbol{v}$.

On the boundaries $\tilde{A}_{v_{a}}$ and $\tilde{A}_{p}$, prescribed values for velocity and pressure, $\hat{\boldsymbol{v}}$ and $\hat{p}$, respectively, must be specified, while on $\tilde{A}_{\dot{o}}$ the boundary force $\hat{\boldsymbol{t}}$ must be in equilibrium with the stress tensor components $\dot{o}_{i j}$. In Eq. (5), $n_{j}$ is the direction cosine between a vector perpendicular to $\tilde{A}_{\dot{o}}$ and the axis $x_{j}$.

Initial conditions for the pressure and the velocity components at $t=0$ must be given.

\section{The Algorithm for the Flow Simulation}

Expanding the governing equations in a Taylor's series up to second order terms, the algorithm for the flow simulation contains the following steps (Braun, 2002):

1) Calculate $\tilde{v}_{i}^{n+1 / 2}$ with:

$$
\begin{aligned}
& \tilde{v}_{i}^{n+1 / 2}=v_{i}^{n}+\frac{\ddot{A} t}{2}\left\{-r_{j} \frac{\partial v_{i}}{\partial x_{j}}-\frac{1}{\tilde{n}} \frac{\partial p}{\partial x_{j}} \ddot{a}_{i j}+\right. \\
& \left.\frac{\partial}{\partial x_{j}}\left[\hat{i}\left(\frac{\partial v_{i}}{\partial x_{j}}+\frac{\partial v_{j}}{\partial x_{i}}\right)+\ddot{e} \frac{\partial v_{k}}{\partial x_{k}} \ddot{a}_{i j}\right]^{n}+\left(\frac{\ddot{A} t}{4} r_{j} r_{k}\right) \frac{\partial^{2} v_{i}^{n}}{\partial x_{j} x_{k}}\right\}
\end{aligned}
$$

where $r_{j}=\left(v_{j}-w_{j}\right)$ and $\bar{v}=\left(v+v_{t}\right)$.

2) Calculate $p^{n+1 / 2}$ with:

$$
p^{n+1 / 2}=p^{n}+\frac{\ddot{A} t}{2}\left\{\left[-r_{j} \frac{\partial p}{\partial x_{j}}-\tilde{n} c^{2} \frac{\partial v_{j}}{\partial x_{j}}\right]^{n}+\left(\frac{\ddot{A} t}{4} r_{i} r_{j}\right) \frac{\partial^{2} p^{n}}{\partial x_{j} \partial x_{i}}\right\}
$$

3) Calculate $\ddot{A p}^{n+1 / 2}=p^{n+1 / 2}-p^{n}$.
4) Calculate $v_{i}^{n+1 / 2}$ with:

$$
v_{i}^{n+1 / 2}=\widetilde{v}_{i}^{n+1 / 2}-\frac{1}{\tilde{n}} \frac{\ddot{A} t^{2}}{8} \frac{\partial \ddot{A} p^{n+1 / 2}}{\partial x_{i}}
$$

5) Calculate $v_{i}^{n+1}=v_{i}^{n}+\ddot{A} v_{i}$ with:

$$
\begin{aligned}
& \ddot{A} v_{i}=\ddot{A} t\left\{-r_{j} \frac{\partial v_{i}}{\partial x_{j}}-\frac{1}{\tilde{n}} \frac{\partial p}{\partial x_{j}} \ddot{a}_{i j}+\frac{\partial}{\partial x_{j}}\left[\hat{i}\left(\frac{\partial v_{i}}{\partial x_{j}}+\frac{\partial v_{j}}{\partial x_{i}}\right)+\right.\right. \\
& \left.\left.\ddot{e} \frac{\partial v_{k}}{\partial x_{k}} \ddot{a}_{i j}\right]\right\}
\end{aligned}
$$

6) Calculate $p^{n+1}=p^{n}+\ddot{A} p$ with:

$$
\ddot{A p}=\ddot{A} t\left\{-r_{j} \frac{\partial p}{\partial x_{j}}-\tilde{n} c^{2}\left(\frac{\partial v_{j}}{\partial x_{j}}\right)\right\}^{n+1 / 2}
$$

These expressions must be employed after applying the classical Galerkin technique into the finite element method $(M E F)$ context.

As the scheme is explicit, the resulting system is conditionally stable, with a stability condition given by:

$$
\ddot{A}_{i}<\dot{a} \frac{\ddot{A} x_{i}}{c+v_{i}}(\mathrm{i}=1, \ldots, N T E)
$$

where $\dot{a}$ (which is a real number less than one) is a safety coefficient, $\ddot{A} x_{i}$ and $v_{i}$ are the i-th element characteristic dimension and the velocity, respectively, and NTE is the total number of elements.

Although variable time step could be adopted (Teixeira \& $A w_{r u c h}$, 2001), in this work an unique value of $\ddot{A} t$ will be used for the whole process, adopting the smallest one from those obtained by Eq. (12).

\section{The Fluid-Structure Coupling}

In the present work, the structure is idealized as a twodimensional rigid body. Displacement and rotations take place on the plane formed by the axis $x_{1}$ and $x_{2}$; the body is restricted by dampers and springs, as indicated in Fig. 1.

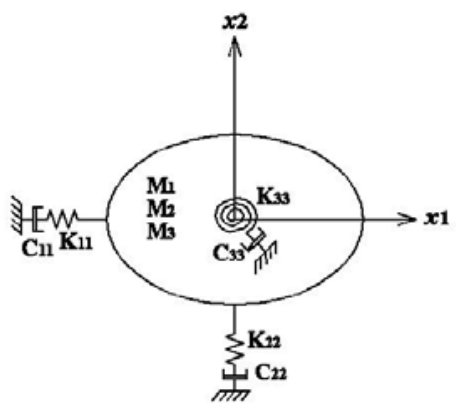

Figure 1. Structure model, formed by a rigid body restricted by springs and dampers. Structure degrees of freedom: $u_{1}=$ displacement in the direction of axis $x_{1} \cdot u_{2}=$ displacement in the direction of axis $x_{2}$. è = rotation around the axis $x_{3}$ (perpendicular to the plane formed by the axes $x_{1}$ and $\left.x_{2}\right)$. 
The structural dynamic equilibrium equation is given by the following matrix expression:

$$
\underset{\sim S \sim S}{M} \underset{\sim S}{\ddot{U}^{c}}+\underset{\sim}{C} \underset{\sim}{\dot{U}^{c}}+\underset{\sim S}{K} \underset{\sim S}{U^{c}}=\underset{\sim S}{Q^{c}}
$$

where $\underset{\sim S}{M}$ is the mass matrix, $\underset{\sim S}{C}$ the damping matrix, $\underset{\sim S}{K}$ the

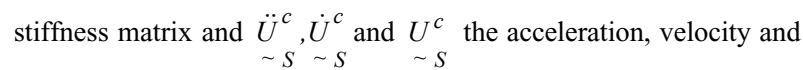
generalized displacements, respectively. Finally, $\underset{\sim S}{Q^{c}}$ is the load vector.

The subscript $S$ means that these matrices belong to the structure and the superscript $C$ indicates that these values correspond to the gravity center of the solid body. Equation (13) can be written as follows:

$$
\begin{aligned}
& {\left[\begin{array}{ccc}
M_{1} & 0 & 0 \\
0 & M_{2} & 0 \\
0 & 0 & M_{3}
\end{array}\right]\left\{\begin{array}{l}
\ddot{u}_{1} \\
\ddot{u}_{2} \\
\ddot{e}
\end{array}\right\}+\left[\begin{array}{ccc}
C_{11} & 0 & 0 \\
0 & C_{22} & 0 \\
0 & 0 & C_{33}
\end{array}\right]\left\{\begin{array}{l}
\dot{u}_{1} \\
\dot{u}_{2} \\
\dot{e}
\end{array}\right\}+} \\
& {\left[\begin{array}{ccc}
K_{11} & 0 & 0 \\
0 & K_{22} & 0 \\
0 & 0 & K_{33}
\end{array}\right]\left\{\begin{array}{l}
u_{1} \\
u_{2} \\
\dot{e}
\end{array}\right\}=\left\{\begin{array}{l}
Q_{S 1}^{c} \\
Q_{S 2}^{c} \\
M_{x 3}^{c}
\end{array}\right\}}
\end{aligned}
$$

It must be noticed that the hypothesis of a rigid structure is proper when deformations of the cross-section are small compared to the rotation and displacement components.

At the solid-fluid interface, the compatibility condition must be satisfied, or in other words, the fluid velocity and the structure velocity must be the same at the common nodes of both fields. The compatibility condition and the translation of variables evaluated at the center of gravity of the body to a point located at the fluidstructure interface may be written with the following expressions:

$$
\underset{\sim S}{\dot{U}^{I}}=\underset{\sim F}{V_{\sim}^{I}}=\underset{\sim}{L} \underset{\sim S}{\dot{U}^{c}} \text { with } \underset{\sim}{L}=\left[\begin{array}{ccc}
1 & 0 & -l_{2} \\
0 & 1 & l_{1}
\end{array}\right]
$$

where $S$ and $F$ are referred to the structure and the fluid, respectively, and the superscript $I$ is referred to the interface. It is important to notice that the both vectors $\underset{\sim S}{\underset{\sim}{U^{I}}}$ and $\underset{\sim F}{V^{I}}$ have two components that correspond to the global axis direction. However, $\underset{\sim S}{\dot{U}^{c}}$ has three components, because it includes the rotation around an axis perpendicular to the plane formed by $x_{1}$ and $x_{2}$. Values of $\underset{\sim S}{\dot{U}^{c}}$ can be transported to the solid-fluid interface (or to nodes belonging to the structure boundary) through a translation matrix $L$, as given by Eq. (15), being $l_{1}$ and $l_{2}$ the distance components between the gravity center of the body and the point under consideration, measured in the global system. Considering Fig. 2, it is observed that the distance components from a boundary point to the body gravity center are functions of $\dot{e}$, and it may be written as follows:

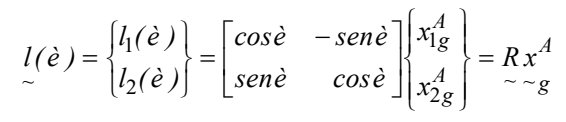

Deriving Eq. (15) with respect to time, taking into account matrix $L$ and equation (16), the following expression is obtained:

$$
\left.\underset{\sim S}{\ddot{U}^{I}}=\underset{\sim F}{\dot{V}^{I}}=\underset{\sim}{L} \underset{\sim S}{\ddot{U}^{c}}+\underset{\sim}{L^{\prime}(\dot{e})} \underset{\sim S}{\dot{U}^{c}} \text {, where } \underset{\sim}{L^{\prime}(\dot{e}}\right)=\left[\begin{array}{ccc}
0 & 0 & -l_{1} \dot{\dot{e}} \\
0 & 0 & -l_{2} \dot{\dot{e}}
\end{array}\right]
$$

Equation (15) and Eq. (17) are applied to each node at the interface, where the equilibrium condition must be also satisfied, that means that the load $S$ acting on the structure at the interface, must be equal to the load $S$ given by Eq. (5), but with an opposite signal (because here the fluid action on the structure is considered, while Eq. (5) represents the boundary action on the fluid). $S$ can be transported to the center of gravity of the body, obtaining:

$$
\underset{\sim S}{Q^{c}}=-\int_{\tilde{A} S} L_{\sim}^{T} \underset{\sim}{S} d \tilde{A}
$$

where $L^{T}$ is the transpose matrix of $L$, given by Eq. (15), and $S$ contains the two components of the fluid boundary force acting on the structure at a point located on the structure surface $\tilde{A}_{S}\left(\tilde{A}_{S}\right.$ represents also the solid-fluid interface); these forces $S$ are given by Eq. (5), but with an opposite signal.

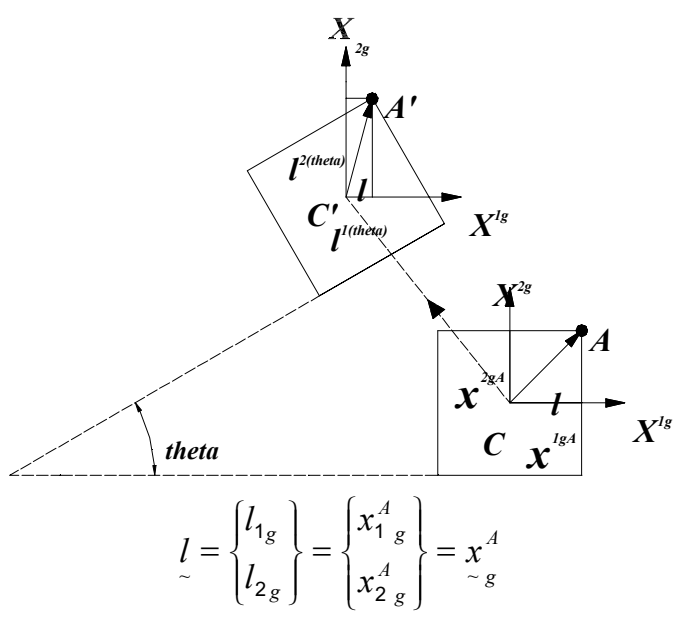

Figure 2. Rigid body motion. The subscripts "g" and "I" are referred to quantities related to global and local axis, respectively.

To determine the coupling effects between the fluid and the structure, in the finite element method (FEM) context, consider an element belonging to the fluid domain in contact with the solid body, as indicated in Fig. 3, where it can be observed that only points 1 and 2 are in contact with the structure. 


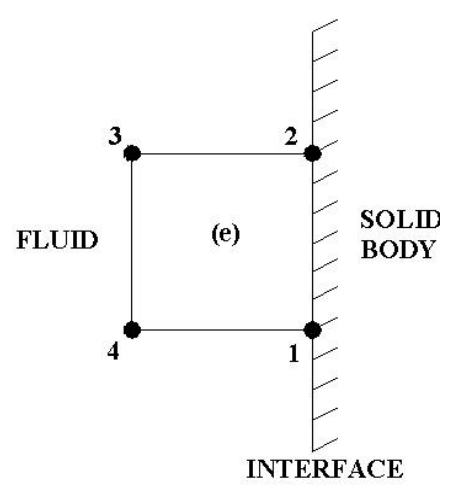

Figure 3. Element of the fluid domain in contact with the solid body.

The momentum equations in its matricial form, at element level (e), can be obtained by applying the Galerkin method to the Eq. (1), writting:

$$
\begin{aligned}
& {\left[\begin{array}{cc}
M M^{I I} & \underset{\sim}{M} \\
\underset{\sim}{M M^{F I}} & \underset{\sim}{M} M^{F F}
\end{array}\right]\left\{\begin{array}{l}
\dot{V}_{\sim}^{I} \\
\underset{\sim}{\dot{V}^{F}}
\end{array}\right\}+\left[\begin{array}{cc}
A D^{I I} & A D^{I F} \\
\sim & \sim \\
A D^{F I} & A D^{F F}
\end{array}\right]\left\{\begin{array}{l}
V^{I} \\
\sim \\
V^{F} \\
\sim
\end{array}\right\}=} \\
& \frac{1}{\tilde{n}}\left\{\begin{array}{c}
\underset{\sim}{G} P^{I} \\
\underset{\sim}{\sim}
\end{array}\right\}+\left\{\begin{array}{l}
\underset{\sim}{S^{I}} \\
S_{\sim}^{F}
\end{array}\right\}
\end{aligned}
$$

where $M M$ contains the time derivative coefficients from the velocity components $V, A D$ contains the coefficients of advective and diffusive terms, GP contains the coefficients of pressure derivative terms with respect to $x_{1}$ and $x_{2}$ and, finally, $S$ is a vector containing the boundary integrals resulting from the integration by parts of pressure and diffusive terms.

In Eq. (19), $\dot{V}^{I}$ and $V^{I}$ contain, respectively, acceleration and velocity components corresponding to nodes 1 and 2 of Fig. 3, while $\dot{V}^{F}$ and $V^{F}$ contain variables corresponding to nodes 3 and 4 of the same figure. A similar remark can be made with respect to the vectors of pressure gradients $G P$ and boundary forces $S$. Matrix

$M M^{I I}$ contains elements coming from the connection of node 1 with itself and with node 2 , and the connection of node 2 with itself and with node 1. Matrix $M M^{I F}$ reflects the connection between the nodes 1 with 4 and 2 with 3 . Similar commentaries can be made with respect to matrices $A D^{I I}$ and $A D^{I F}$.

Regarding the structural analysis, only the first matricial expression of Eq. (19) is necessary, because only this equation contributes to the assembling of the overall dynamic equilibrium equation. On the other hand, as the structural and the flow analysis are performed in a sequential form in this work, the system constituted by the solid body and fluid elements with one or more sides common to the solid-fluid interface have prescribed values of $V$ and $P$ at nodes that do not have any contact with the structure (they were calculated previously in the flow analysis). Referring to Fig. 3, at nodes 3 and 4, the values $\underset{\sim}{V^{F}}$ and $\underset{\sim}{P^{F}}$ are known. All these considerations lead to the elimination of the second expression of Eq. (19) when the governing equations which describe the solid body motion are built, taking into account the solid-fluid coupling effect. The first expression of Eq. (19) can be re-written as:

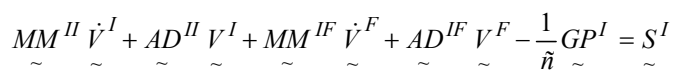

Equation (15) with matrix $L$ and Eq. (17) with matrix $L^{\prime}(\dot{\dot{e}})$ are considered for each node at the interface. Then, when an element side with two nodes and lying on the fluid-structure interface is considered, Eq (15) and Eq. (17) are written in the following form:

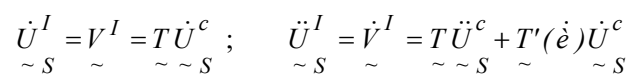

Referring again to Fig. 3, the matrices $T$ and $T^{\prime}$ are given by:

$$
\underset{\sim}{\sim}=\left[\begin{array}{rrr}
1 & 0 & -l_{2}^{1} \\
0 & 1 & l_{1}^{1} \\
1 & 0 & -l_{2}^{2} \\
0 & 1 & l_{1}^{2}
\end{array}\right]=\left[\begin{array}{l}
L \\
\underset{\sim}{L}
\end{array}\right] ; \quad T_{\sim}^{\prime}(\dot{\dot{e}})=\left[\begin{array}{ccc}
0 & 0 & -l_{1}^{1} \\
0 & 0 & -l_{2}^{1} \\
0 & 0 & -l_{1}^{2} \\
0 & 0 & -l_{2}^{2}
\end{array}\right] \dot{\dot{e}}=\left[\begin{array}{l}
\underset{\sim}{L^{\prime}(\dot{e})} \\
\left.\underset{L^{\prime}(\dot{\dot{e}})}{L^{\prime}}\right]
\end{array}\right]
$$

The contribution from $S^{I}$, on the side 1-2 of the element (e), to the total load acting at the gravity center of the body, can be calculated as:

$$
\hat{Q}_{S}^{c}=-T^{T} S_{\sim}^{I}
$$

Considering Eqs. (14), (15), (17) and (20), with the last one multiplied by $\tilde{n}$, the structural dynamic equilibrium equation, taking into account the solid-fluid coupling effect, is given by:

$$
\begin{aligned}
& {\left[\underset{\sim S}{M}+\sum_{i=1}^{N T L}\left({\underset{\sim}{\sim}}_{\sim}^{T} \underset{\sim}{M M^{I I}} \underset{\sim}{\sim}\right)_{i}\right] \ddot{\sim}_{\sim S}^{c}+} \\
& {\left[\underset{\sim S}{C}+\sum_{i=1}^{N T L}({\underset{\sim}{T}}^{T} \rho \underset{\sim}{A D^{I I}} \underset{\sim}{\sim}+\underbrace{T}_{\sim} \rho \underset{\sim}{M} M^{I I} T_{\sim}^{\prime})_{i}\right] \underset{\sim S}{\dot{U}^{c}}+\underset{\sim S}{K} U^{c}=} \\
& -\left[\sum_{i=1}^{N T L}\left(\underset{\sim}{T^{T} \rho M M^{I F}} \underset{\sim}{\dot{V}^{F}}+\underset{\sim}{T^{T}} \rho \underset{\sim}{A D^{I F}}{\underset{\sim}{V}}^{F}-\underset{\sim}{T^{T}} \underset{\sim}{G P^{I}}\right)_{i}+\underset{\sim S}{Q^{c}}\right]
\end{aligned}
$$

where NTL is the total number of fluid elements in contact with the structure, having at least one straight segment common to the solid body surface, forming the solid-fluid interface. The matricial Eq. (24) is re-written as:

$$
\underset{\sim S \sim S}{\bar{M}} \underset{\sim S}{\ddot{U}^{c}}+\bar{C} \underset{\sim S}{\dot{U}^{c}}+\underset{\sim S}{K} \underset{\sim S}{U^{c}}=\underset{\sim S}{\bar{Q}^{c}}
$$


As can be noticed, $\underset{\sim}{\bar{C}}$ is a non-symmetric matrix, because it contains the advective terms and $\left[T_{\sim}^{T} \underset{\sim}{M} M^{I I} T_{\sim}^{\prime}(\dot{\dot{e}})\right]$. This last term leads to the non-linearity of matrix $\underset{\sim S}{\bar{C}}$.

In this work, a monolithic coupling between fluid and structure was not considered. The analysis for both fields is made in a sequential way. Firstly, Eq. (6) to Eq. (11) are solved, with the smallest $\ddot{A} t$ calculated with Eq. (12) and applying the boundary conditions given by Eq. (3) to Eq. (5). After, Eq. (25) is solved using the Newmark's method (Bathe, 1996). Although different time steps may be used for the fluid and the structure, here the same time step was adopted, because the computer time required by the structure analysis is negligible with respect to the processing time demanded by the flow analysis. Furthermore, compatibility and equilibrium conditions are more accurately imposed if the same time intervals are employed.

\section{Strouhal Number and Aerodynamic Coefficients Calculation}

The Strouhal number $(S t)$ can be calculated with $S t=\frac{f_{v} L_{0}}{V_{0}}$,

where $V_{0}$ is a reference velocity, $L_{0}$ a reference dimension and $f_{v}$ is the shedding frequency of a pair of vortices. It depends of the immersed prism cross-section, its oscillations, its superficial details, the Reynolds number and the flow characteristics. Formulation to calculate this number is presented in many publications and texts (for example, Schlichting, 1979). When the Strouhal number of a flow with a given immersed structure is known, it is possible to obtain the velocity $V_{0_{R}}$, which will produce the resonant phenomenon on the vibrating body. It occurs when the shedding frequency of a pair of vortices is approximately equal to the structural natural frequency.

The drag coefficient $C_{D}$ is related to the acting forces on the structure in the flow direction, while the lift coefficient $C_{L}$ is related to the acting forces on the structure in the transversal-to-flow direction. Finally, the pitching moment coefficient $C_{M}$ is related to the torsional moment acting at the gravity center of the immersed prism. The three coefficients can be calculated using the following expressions:

$$
C_{D}=\frac{\sum_{i=1}^{N T N} S_{1_{i}}^{I}}{\frac{1}{2} \tilde{n} V_{0}^{2} L_{0}} ; C_{L}=\frac{\sum_{i=1}^{N T N} S_{2_{i}}^{I}}{\frac{1}{2} \tilde{n} V_{0}^{2} L_{0}} ; C_{M}=\frac{\sum_{i=1}^{N T N}\left(-S_{1_{i}}^{I} l_{2 i}+S_{2 i}^{I} l_{1 i}\right)}{\frac{1}{2} \rho\left(V_{0} L_{0}\right)^{2}}
$$

where $S_{1}^{I}$ and $S_{2}^{I}$ are the forces in the directions $x_{1}$ and $x_{2}$, respectively, acting on the structure at node $i$, located on the interface. $l_{1 i}$ and $l_{2 i}$ are the projections in the directions $x_{1}$ and $x_{2}$, respectively, of the distance between the gravity center and node $i$. NTN is the total number of nodes located on the solid-fluid interface. The forces $S_{1}^{I}$ and $S_{2}^{I}$ are the components of the force vector $S^{I}$, given by Eq. (20). These forces are applied to the structure on each fluid element side belonging to the interface.

The pressure coefficient at a point $i, C_{p}^{i}$, located on the interface, is related to the pressure acting at that point. This coefficient can be calculated using the following expression:

$$
C_{p}^{i}=\frac{P_{i}-P_{0}}{\frac{1}{2} \tilde{n} V_{0}^{2}}
$$

where $P_{i}$ is the pressure at node $i$ and $P_{0}$ is a reference pressure (for example, the pressure in an undisturbed area of the flow). With the instantaneous values of pressure coefficients, the time history may be obtained and then the mean pressure distribution on the body surface, for a given time interval, may be calculated.

\section{The Automatic Mesh Motion Scheme}

Taking into account that the immersed body in the fluid can move and rotate in its plane and that the flow is described by an Arbitrary Lagrangean-Eulerian $(A L E)$ formulation, a scheme for the mesh motion is necessary, establishing the velocity field $\boldsymbol{w}$ in the fluid domain, such that the element distortion will be as smaller as possible, according to the following boundary conditions:

$$
\left.\boldsymbol{w}\right|_{\text {int erface }}=\underset{\sim F}{V^{I}}=\dot{U}_{\sim E}^{I} ;\left.\boldsymbol{w}\right|_{\text {boundaries }} ^{\text {external }}=0
$$

In the present work, the mesh motion scheme is similar to that used by Teixeira $\&$ Awruch $^{\mathrm{b}}$ (2001). Considering that $i$ is an inner point in the fluid field and $j$ is a boundary node, the mesh velocity components at node $i$, in the direction of the axis $x_{k}$, are given by:

$$
w_{k}^{i}=\frac{\sum_{j=1}^{N S} a_{i j} w_{k}^{j}}{\sum_{j=1}^{N S} a_{i j}}(\mathrm{k}=1,2)
$$

where $N S$ is the total number of nodes belonging to the boundary lines and $a_{i j}$ are the influence coefficients between the inner points and the boundary lines of the flow field, being $a_{i j}=\frac{1}{\left(d_{i j}\right)^{n}}$, where $d_{i j}$ is the distance between $i$ and $j$, and $n \geq 1$. The exponent $n$ can be adjusted by the user. Although regions with purely Eulerian and purely Lagrangean descriptions mat be used simultaneously with the $A L E$ formulation, this alternative may result in more complex and less efficient codes. It may also lead to more difficulties to control mesh distortions.

\section{Examples}

\section{Analysis of the Flow Around a Rectangular Prism}

This example presents a prism with a rectangular cross-section free to oscillate in the transversal-to-flow and rotational directions. Through this problem, the program performance for large and coupled motion is observed, even that this cross-section form is not usually employed in bridge structures. In this study, special attention is given to the structural dynamic response in the two degrees of freedom of the cross-section and to the finite element mesh motion, remembering that a special scheme is employed for the non-linear dependence with respect to the cross-section rotation in the compatibility condition at the solid-fluid interface.

In the present section, results obtained for a flow around a rectangular prism with a Reynolds number equal to 1000 are presented. The rectangular cross-section exhibits a height/width relation $(h / B)$ of 0.2 . The geometry and the boundary conditions, in 
a non-dimensional form, are shown in Fig. 4. In addition, initial velocity and pressure field for the fluid-structure interaction problem are those of a developed flow obtained with a fixed body.

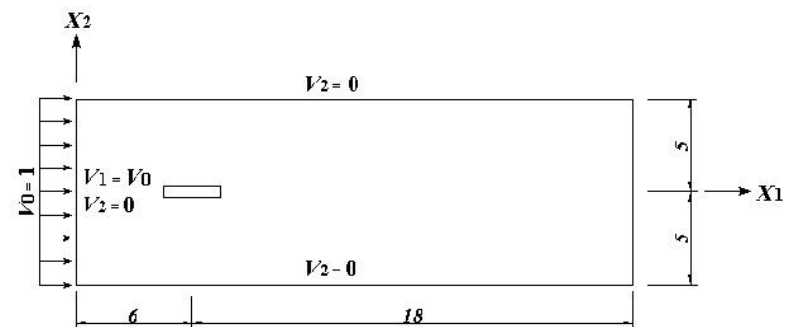

Figure 4. Flow around a rectangular prism: geometry and boundary conditions.

The finite element mesh has 5865 nodes and 5700 quadrilateral bi-linear isoparametric elements and is shown in Fig. 5. A nondimensional time step $\ddot{A} t^{*}=1.0 \times 10^{-4}$ was adopted. The fluid and structural data are presented in Table 1.

Table 1. Rectangular prism: dimensionless data for the fluid and the structure.

\begin{tabular}{|c|c|c|}
\hline \multicolumn{3}{|c|}{ Rectangular Prism - Reynolds 1000} \\
\hline \multirow{6}{*}{ 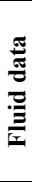 } & Specific mass $(\tilde{n})$ & 1.0 \\
\hline & Volumetric viscosity $(\ddot{e})$ & 0.0 \\
\hline & Reynolds number (Re) & 1000 \\
\hline & Mach number $(M)$ & 0.06 \\
\hline & Reference/inflow velocity $\left(V_{0}\right)$ & 1.0 \\
\hline & Characteristic dimension (D) & 1.0 \\
\hline \multirow{9}{*}{ } & Dimensionless longitudinal stiffness $\left(K^{*}{ }_{11}\right)$ & $3 \times 10^{4}$ \\
\hline & Dimensionless transversal stiffness $\left(K_{22}^{*}\right)$ & 0.7864 \\
\hline & Dimensionless torsional stiffness $\left(K^{*}{ }_{33}\right)$ & 17.05 \\
\hline & Dimensionless longitudinal mass $\left(M_{1}^{*}\right)$ & 195.57 \\
\hline & Dimensionless transversal mass $\left(M_{2}^{*}\right)$ & 195.57 \\
\hline & Dimensionless torsional mass $\left(M_{3}^{*}\right)$ & 105.94 \\
\hline & Dimensionless longitudinal damping $\left(C^{*}{ }_{11}\right)$ & $1 \times 10^{7}$ \\
\hline & Dimensionless transversal damping $\left(C_{22}^{*}\right)$ & 0.0325 \\
\hline & Dimensionless torsional damping $\left(C^{*}{ }_{33}\right)$ & 0.0 \\
\hline
\end{tabular}

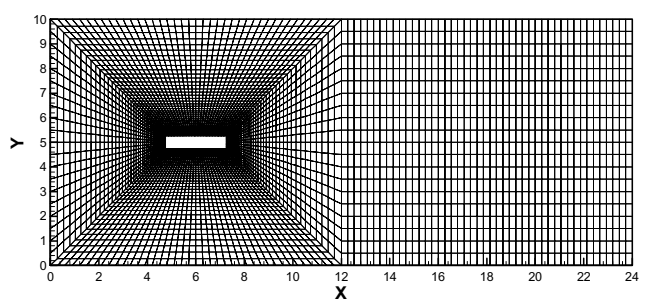

Figure 5. Rectangular prism: finite element mesh.

In Fig. 6 the time histories related to angular and vertical displacements, velocities and accelerations are presented. It is important to notice that the time used in these figures is dimensionless. These results are very similar to those obtained by Sarrate et al. (2001), using a different method.
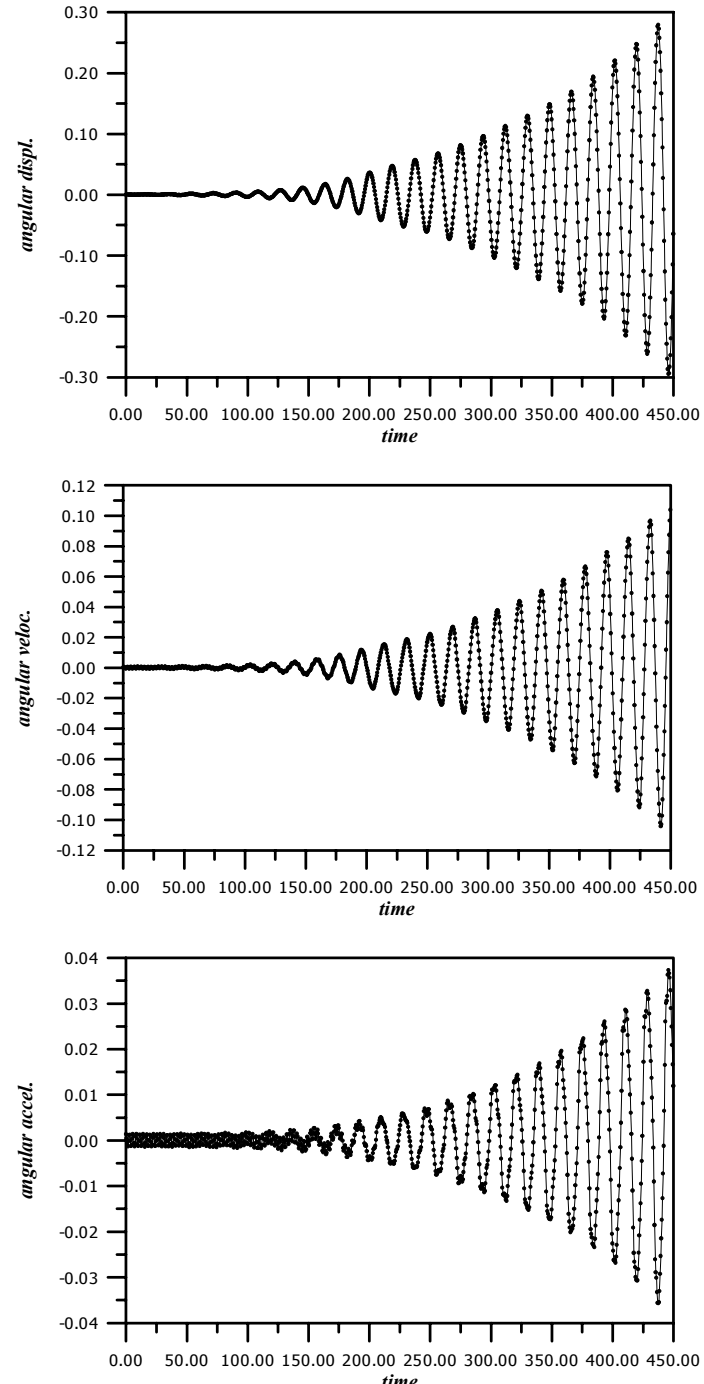

time

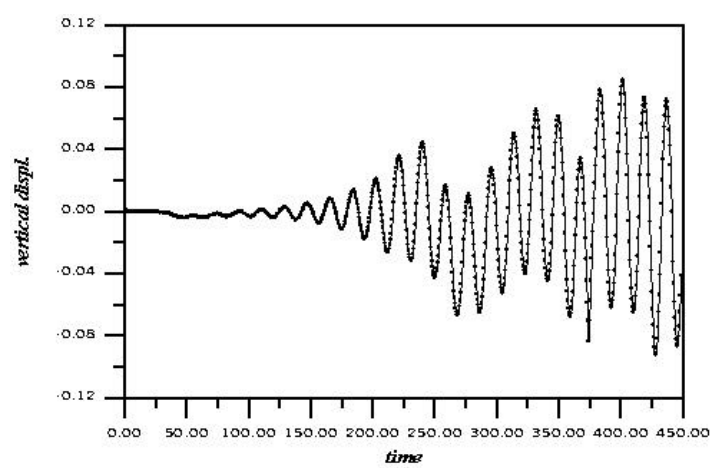

Figure 6. Rectangular prism: time histories of vertical and rotational displacements, velocities and accelerations. 

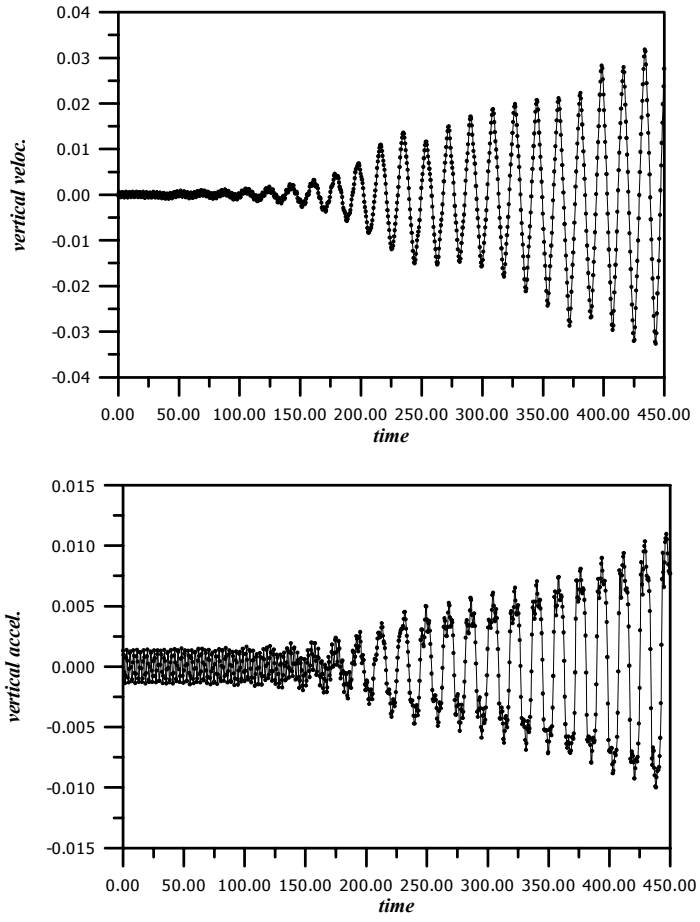

Figure 6. (ontinued).

The streamlines and the pressure field are shown in Fig. 7, in three instants $\left(t^{*}=439, t^{*}=442\right.$ and $\left.t^{*}=448\right)$. It can be observed the presence of high pressure gradients and large vortices alternating between the lower and the higher surfaces. The streamlines show that the cross-section orientation with respect to the free flow direction modifies the boundary layer form. This conclusion is the same observed in bluff bodies, where the flux-ward dimension is one of the parameters that determine the forms of the boundary layer and wake. In Fig. 8 it is verified the distortion of the mesh in an instant where extreme structural rotation is reached.

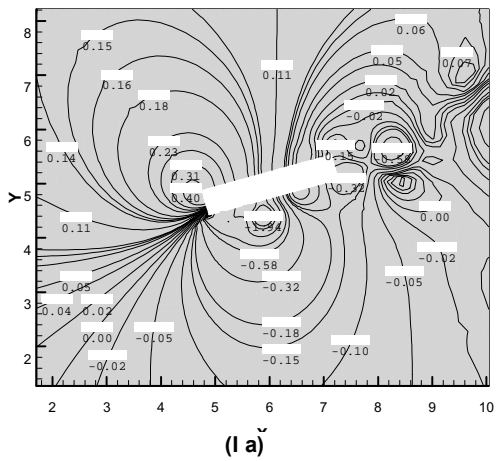

Figure 7. Rectangular prism: (I) pressure contours and (II) streamlines contours; (a) $t^{*}=439$; (b) $t^{*}=442$ and (c) $t^{*}=448$.

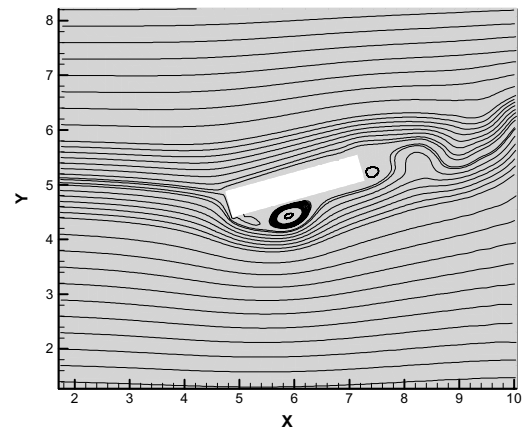

(II a)

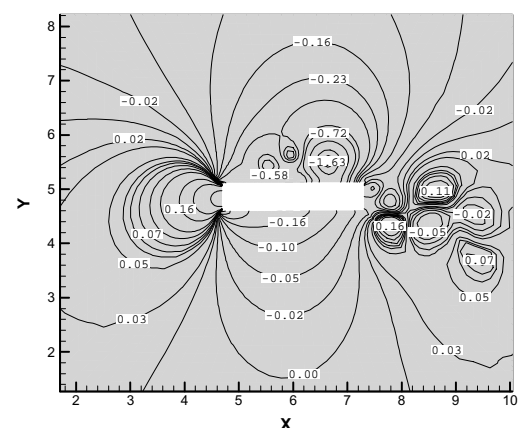

(I b)

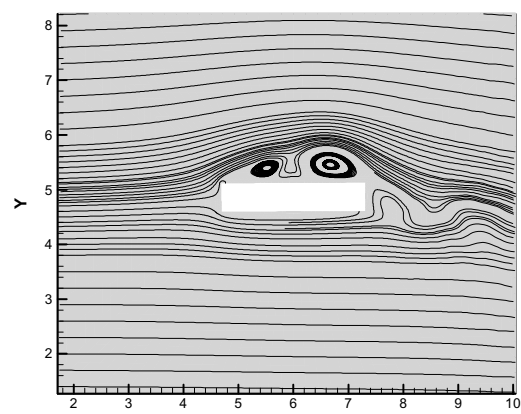

(II b)

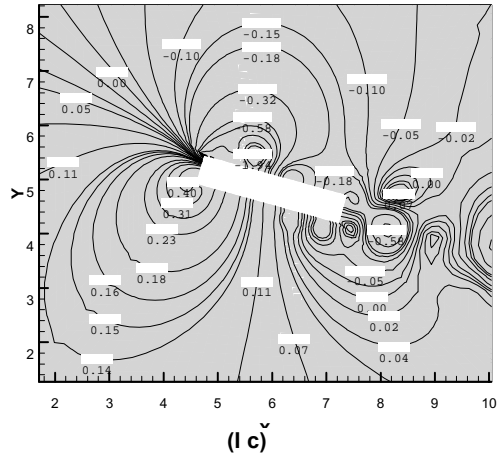

Figure 7. (Continued). 


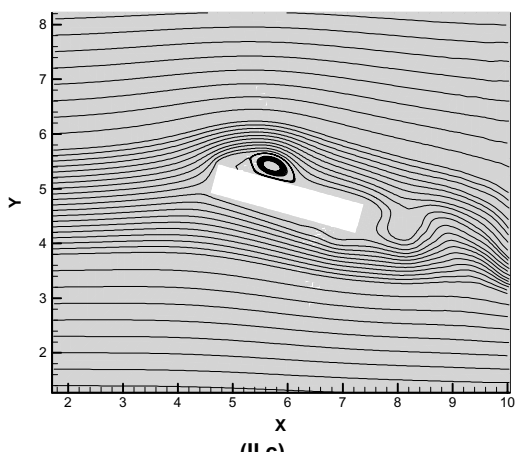

(II c)

Figure 7. (Continued).

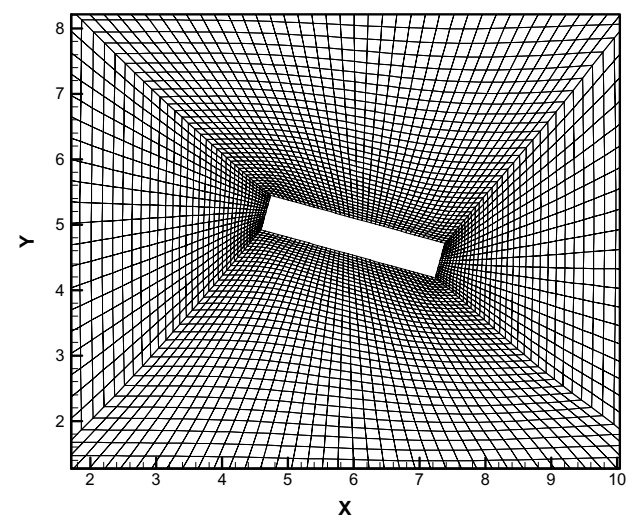

Figure 8. Rectangular prism: finite element mesh at $\mathbf{t}^{*}=448$.

It can be observed that a satisfactory performance has been obtained for this example. The ability of the code to study fluidstructure interaction problems, where immersed bodies move due to the flow action with large displacements and rotations was also confirmed. In addition, the main characteristics of flows around bluff bodies were well simulated. The analysis of this kind of problem is only possible if a special Arbitrary Lagrangean-Eulerian $(A L E)$ description is used. Another important aspect that is the mesh motion model, used previously by Teixeira \& Awruch $^{\mathrm{a}}$ (2001), was applied here with the same success.

\section{Numerical Study of the Great Belt East Bridge Cross-section}

In this section, results of the numerical simulation of the wind action on a cross-section belonging to the Great Belt East Bridge are presented, including the aerodynamic and the aeroelastic behavior. The studies are accomplished by fixed and oscillating sectional models, according to the usual wind tunnel techniques.

The Great Belt East Bridge is located in Denmark, precisely in the Great Belt Channel, an important international shipping route. The design phase was initiated in 1989, being it opened to the traffic in 1998. It is a suspension bridge, with a superstructure constituted by two approaching spans of $535 \mathrm{~m}$ (each one) and a central span of $1624 \mathrm{~m}$, which will be studied in this work. In Fig. 9, general aspects of the bridge are shown. The pictures were taken from Larsen \& Walther (1997).

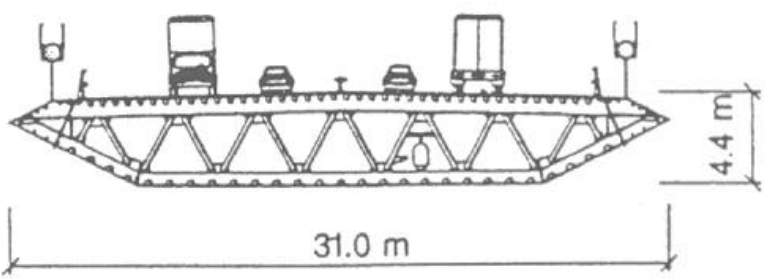

(a)

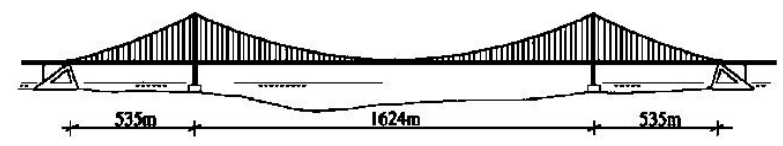

(b)

Figure 9. General characteristics of the Great Belt East Bridge: (a) crosssection; (b) elevation.

Firstly, the fixed cross-section was analyzed and the aerodynamic coefficients were obtained as functions of the angle of attack of the wind direction. The Strouhal number was also calculated. Finally, free oscillations of the cross-section in the vertical and the rotational degrees of freedom were allowed in order to carry out dynamic instability investigations.

\section{Analysis of the Flow Around the Fixed Cross-Section}

The computational domain and the boundary conditions used in this example, are illustrated in Fig. 10. As can be noticed, the inflow boundary conditions are functions of the angle of attack of the wind direction. Four different values of the angle of attack were studied: $10^{\circ},-5^{\circ}, 0^{\circ} \mathrm{e}+5^{\circ}$. The initial pressure and velocity were assumed equal to zero.

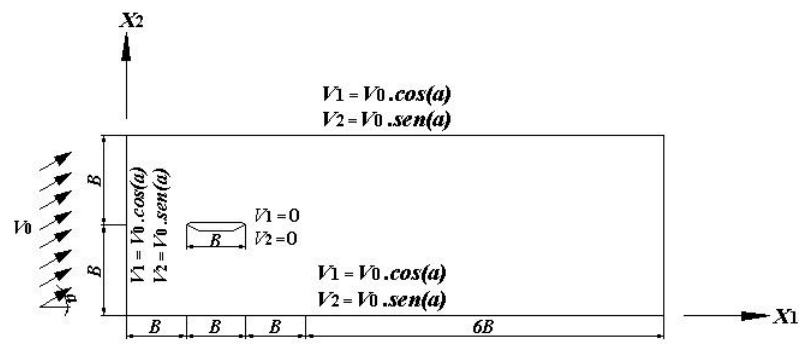

Figure 10. Great Belt East Bridge: geometry and boundary conditions for the fixed cross-section.

The finite element mesh employed in this problem has 8175 bilinear isoparametric elements with 8400 nodes, and is shown in Fig. 11.

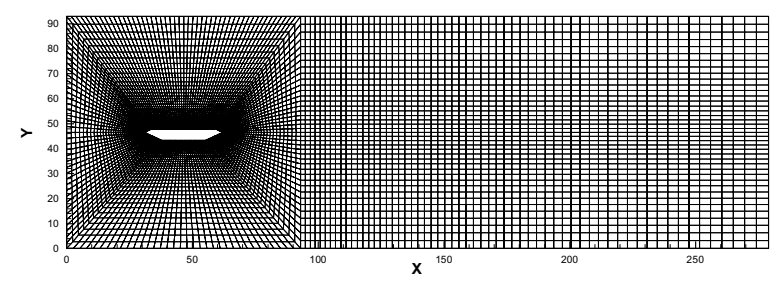

Figure 11. Great Belt East Bridge: finite element mesh. 
The Reynolds number used in the four cases is $3.0 \times 10^{5}$. The other constants used in the analysis are presented in Table 2. From the well-known Courant stability condition, the time step is $\ddot{A} t=$ $1.15 \times 10^{-4} \mathrm{~s}$.

Table 2. Great Belt East Bridge: data used to determine aerodynamic coefficients.

\begin{tabular}{cc}
\hline Constants & $\begin{array}{c}\text { Great Belt East Bridge - } \\
\text { Reynolds 3x10 }\end{array}$ \\
\hline Specific mass $(\tilde{n})$ & $1.32 \mathrm{Kg} / \mathrm{m}^{3}$ \\
\hline Volumetric viscosity $(\ddot{e})$ & $0.0 \mathrm{~m}^{2} / \mathrm{s}$ \\
\hline Kinematic viscosity $(i)$ & $5.78 \times 10^{-4} \mathrm{~m}^{2} / \mathrm{s}$ \\
\hline Sound velocity $(c)$ & $337.0 \mathrm{~m} / \mathrm{s}$ \\
\hline Reference/inflow velocity $\left(V_{0}\right)$ & $40.0 \mathrm{~m} / \mathrm{s}$ \\
\hline Smagorinsky's constant $\left(C_{S}\right)$ & 0.2 \\
\hline Charact. dimension/cross-section $(D)$ & $4.40 \mathrm{~m}$ \\
\hline
\end{tabular}

The investigated mean coefficients, obtained from the time histories, are plotted in Fig. 12 as functions of the angle of attack, and compared with the experimental results given by Reinhold et al. (1992) and the numerical results obtained by Kuroda (1997).

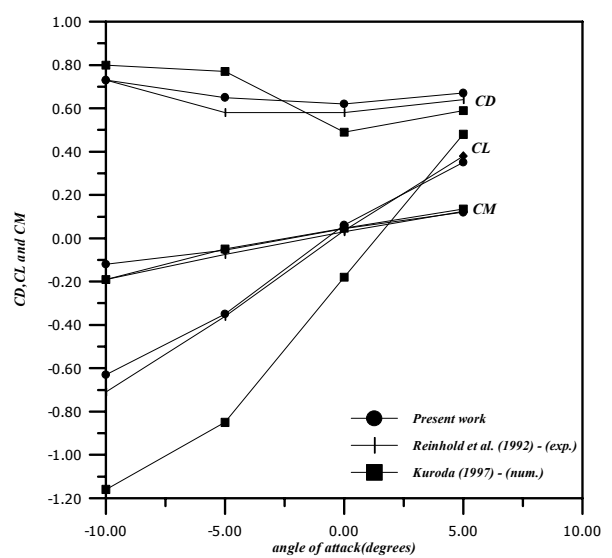

Figure 12. Great Belt East Bridge: numerical and experimental results for aerodynamic coefficients as functions of the angle of attack.

The Strouhal number, obtained from the vertical velocity component time history $V_{2}$ at a point located a distance $0.2 \mathrm{~B}$ behind the cross-section (with zero angle of attack), is 0.18 . Comparisons of some of the results obtained for Strouhal number of the referred bridge are shown in Table 3.

Table 3. Strouhal number for the Great Belt East Bridge.

\begin{tabular}{cc}
\hline Reference & $\begin{array}{c}\text { Strouhal number } \\
\text { - Reynolds } \mathbf{3 x 1 0} \mathbf{5}^{\mathbf{5}}\end{array}$ \\
\hline Present work & 0.180 \\
\hline Larsen et al. (1998) (numer.) & 0.170 \\
\hline Wind tunnel tests (from: Larsen et al. (1998)) & 0.160 \\
\hline
\end{tabular}

The streamlines observed for the different angles of attack are presented in Fig. 13 and are similar to those obtained by Kuroda (1997).

360 / Vol. XXV, No. 4, October-December 2003
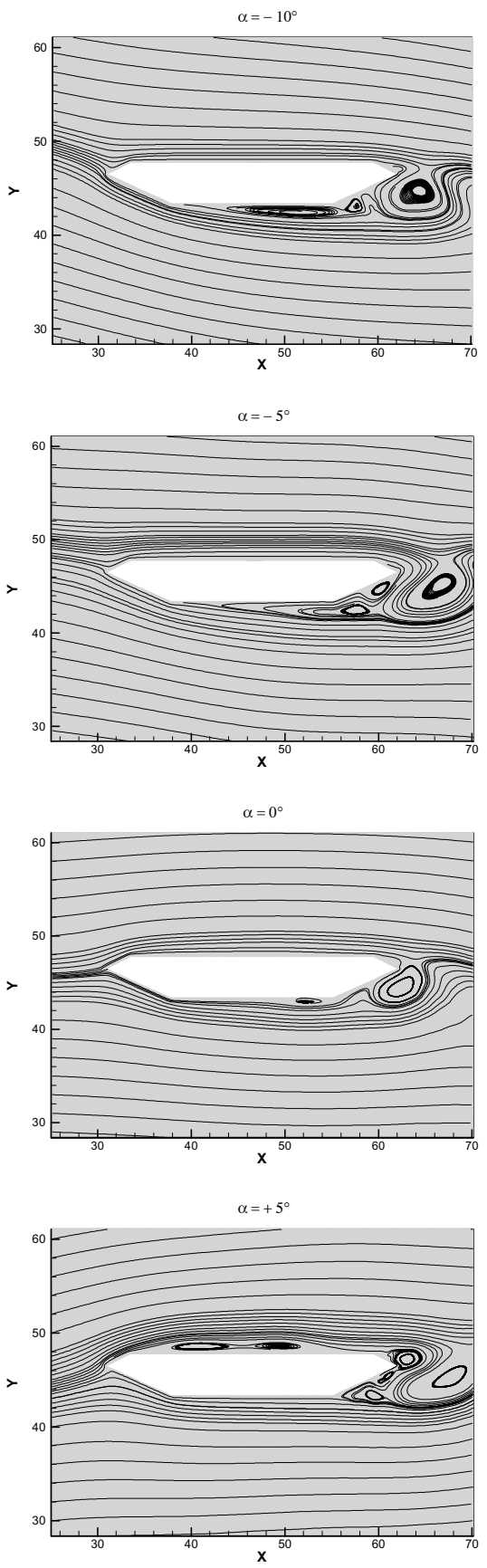

Figure 13. Great Belt East Bridge: streamlines contours for different angles of attack.

\section{Aeroelastic Analysis: Flutter}

In this work, Flutter analysis is accomplished in two different ways: a) direct method, presented by Selvam et al. (2002), and b) using the flutter derivative $A_{2}^{*}$, introduced by Scanlan \& Tomko (1971), being this coefficient related to the aerodynamic damping due to torsional rotations. Both methods have the same experimental procedure and are based on the observation of the structural response to cross-section rotations for various wind velocity values. 
In Selvam et al. (2002), it is shown a method in which the growth/decay rate is determined from the structural response, observed in several reduced wind velocities given by $V^{*}=\frac{V_{0}}{f B}$, where $V_{0}$ is the inflow velocity, $B$ is the bridge deck width and $f$ is the natural structural frequency. These values of the growth/decay rate are calculated with $\tilde{a}_{g / d}=\left(y^{k}-y^{k+1}\right) / y^{k}$, where $y^{k}$ and $y^{k+1}$ are the peak values in the same oscillation period. After, they are transported to a chart in function of the reduced wind velocity, and the critical velocity corresponds to the point where the curve crosses the velocity axis (growth/decay rate $=0$ ).

In the flutter derivatives method (Scanlan \& Tomko, 1971), the experimental damping $\alpha_{\dot{e}}^{e x p}$ and the natural frequency $\grave{u}_{\dot{e}}^{\exp }$ for each reduced wind velocity are obtained from the structural response. These values are introduced into an expression, representing the aerodynamic damping and given by:

$$
A_{2}^{*}\left(V^{*}\right)=\frac{4 I}{\tilde{n} B^{4}}\left[\alpha_{\grave{e}} \frac{\grave{u}_{\grave{e}}}{\grave{u}_{\grave{e}}^{\exp }}-\alpha_{\grave{e}}^{e x p}\right]
$$

where $I$ is the mass moment of inertia, $\tilde{n}$ is the specific mass of the fluid, $B$ is the bridge deck width, $\alpha_{\dot{e}}$ is the structural critical damping and $\grave{u}_{\grave{e}}$ the structural natural frequency. Eq. (30) may be also written, by experimental considerations, in a reduced expression in terms of the logarithmic decrement $\ddot{a}^{\exp } \cong 2 ð e^{\exp }$ as follows:

$$
A_{2}^{*}\left(V^{*}\right)=-\frac{I}{\tilde{n} B^{4}} \frac{2 \ddot{a}_{\dot{e}}^{\exp }}{\partial}
$$

Thus, a curve of this coefficient $A_{2}^{*}$ in function of the reduced wind velocities is built. The critical flutter velocity is obtained by a critical condition expressed by:

$$
A_{2}^{*}=\frac{4 I \omega_{e}}{\tilde{n} B}
$$

So, when $A_{2}^{*}>4 I c_{\grave{e}} / \tilde{n} B$ the aerodynamic damping is greater than the structural damping, originating negative damping and oscillations with growing amplitudes.

The geometry as well as the finite element mesh employed in the determination of the critical velocity of flutter is the same that was used previously (Fig. 10 and Fig. 11). Initially, a fixed crosssection with an inclination of $1.8^{\circ}$ was taken. After 30000 time steps, the load boundary conditions at the body surface were computed, and then, the body motion was allowed. The outflow boundary conditions were kept identical to the case where the body remains fixed with zero angle of attack, with exception to the inflow velocity, which changes in order to obtain the desired curves.

The physical properties and design values of the structure, employed in the experiments, are found in Table 4. The structure is idealized such that only torsional rotations are allowed (because it was verified that coupling vertical displacements and rotations will not modify significativelly the critical velocity of flutter).

The problem was analyzed for four reduced velocities: 2, 4, 6 and 10 . These values correspond to the following inflow velocities: $16.86 \mathrm{~m} / \mathrm{s}, 33.73 \mathrm{~m} / \mathrm{s}, 50.59 \mathrm{~m} / \mathrm{s}$ and $84.32 \mathrm{~m} / \mathrm{s}$, respectively. The flow was analyzed with $R e=10^{5}$.
Table 4. Great Belt East Bridge: structural data used in the flutter analysis.

\begin{tabular}{cc}
\hline \multicolumn{3}{c}{ Great Belt East Bridge - Reynolds $\mathbf{1 0}^{\mathbf{5}}-$ Structural data } \\
\hline Longit. and transv. stiffness $\left(K_{11}, K_{22}\right)$ & $3 \times 10^{9} \mathrm{~N} / \mathrm{m} . \mathrm{m}$ \\
\hline Torsional stiffness $\left(K_{33}\right)$ & $7.21 \times 10^{6} \mathrm{~N} \cdot \mathrm{m} / \mathrm{rad} . \mathrm{m}$ \\
\hline Longit. and transv. mass $\left(M_{1}, M_{2}\right)$ & $2.27 \times 10^{4} \mathrm{~N} . \mathrm{s}^{2} / \mathrm{m} . \mathrm{m}$ \\
\hline Torsional mass $\left(M_{3}\right)$ & $2.47 \times 10^{6} \mathrm{~N} \cdot \mathrm{m} . \mathrm{s}^{2} / \mathrm{rad} . \mathrm{m}$ \\
\hline Longit. and transv. damping $\left(C_{11}, C_{22}\right)$ & $3 \times 10^{4} \mathrm{~N} . \mathrm{s} / \mathrm{m} . \mathrm{m}$ \\
\hline Torsional damping $\left(C_{33}\right)$ & $0.00 \mathrm{~N} . \mathrm{m} . \mathrm{s} / \mathrm{rad} . \mathrm{m}$ \\
\hline Vertical natural frequency $\left(f_{h}\right)$ & $0.099 \mathrm{~Hz}$ \\
\hline Angular natural frequency $\left(f_{e}\right)$ & $0.272 \mathrm{~Hz}$ \\
\hline Critical damping $(c)$ & 0.002 \\
\hline
\end{tabular}

In Fig. 14, time histories related to the angular displacement are presented for each reduced wind velocity. From the rotation time histories, the growth/decay rate as well as the logarithmic decrement for each reduced velocity were obtained. In Table 5 all these values are presented.
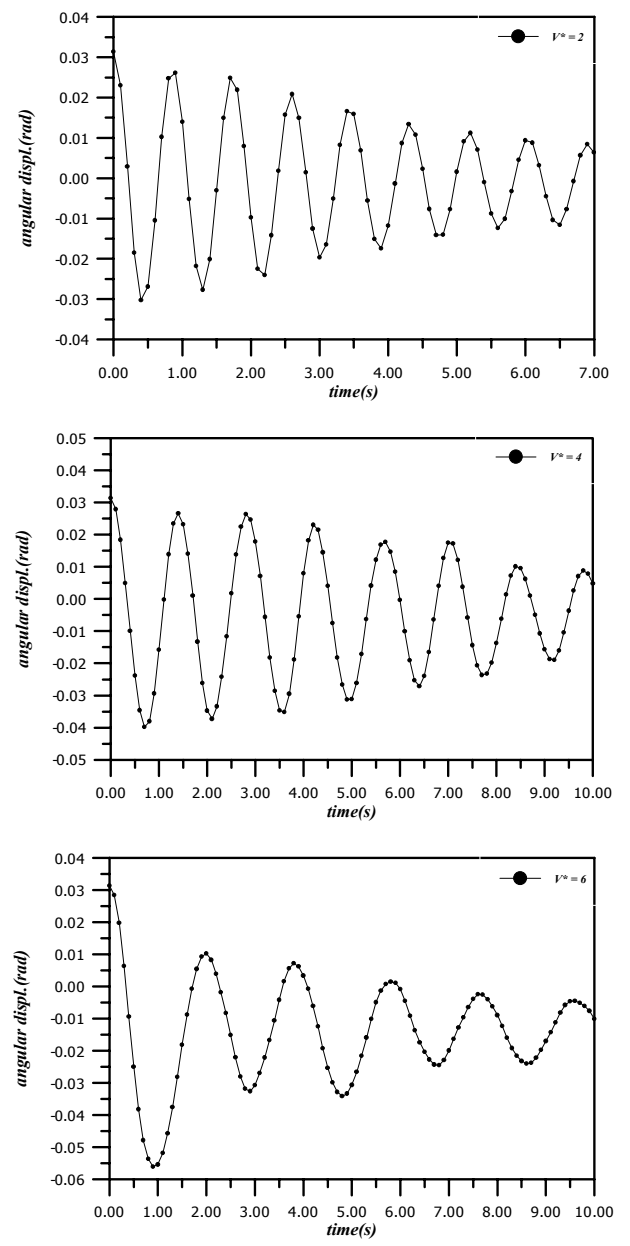

Figure 14. Great Belt East Bridge: angular displacement time histories for the studied reduced wind velocities. 


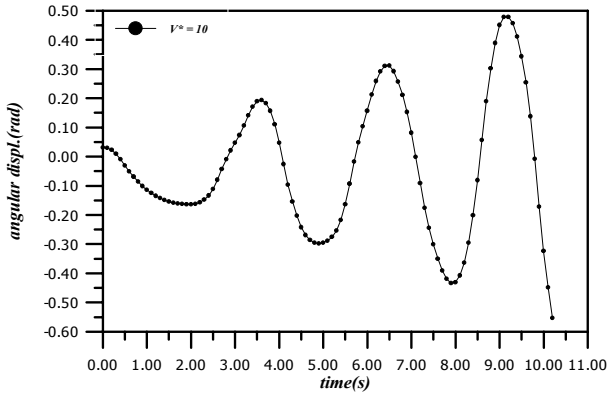

Figure 14. (Continued).

Table 5. Great Belt East Bridge: numerical results for flutter analysis.

\begin{tabular}{ccccc}
\hline \multirow{2}{*}{ Results } & \multicolumn{4}{c}{ Great Belt East Bridge - Reynolds } \\
\cline { 2 - 5 } & $\boldsymbol{V}^{*}=\mathbf{2}$ & $\boldsymbol{V}^{*}=\mathbf{4}$ & $\boldsymbol{V}^{*}=\mathbf{6}$ & $\boldsymbol{V}^{*}=\mathbf{1 0}$ \\
\hline Growth/decay rate & 0.131 & 0.270 & 0.311 & -0.500 \\
\hline Logarithmic decrement & 0.176 & 0.205 & 0.291 & -0.403 \\
\hline
\end{tabular}

In Fig. 15 the curves to obtain the critical velocity of flutter by the direct method of Selvam et al. (2002) and by the flutter derivative $A_{2}^{*}$ (Scanlan \& Tomko, 1971), respectively, are presented.

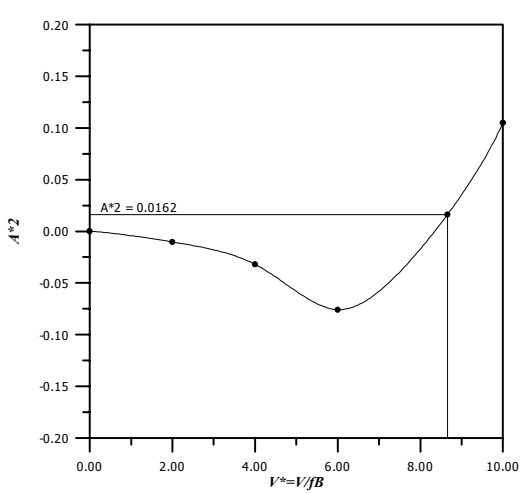

(a)

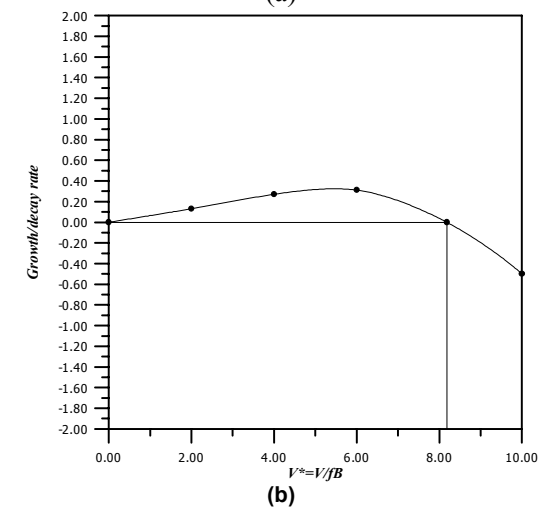

Figure 15. Flutter analysis: (a) by the flutter derivative $A_{2}^{*}$ and (b) by the direct method for the Great Belt East Bridge.

From Fig. 15, the reduced critical velocity obtained by the direct method is 8.18 , corresponding to a velocity of $69 \mathrm{~m} / \mathrm{s}$. By the flutter derivative method, considering the critical condition as $A_{2}^{*} \geq$ $1.62 \times 10^{-2}$, yields a reduced velocity equal to 8.66 which corresponds to a critical velocity equal to $73 \mathrm{~m} / \mathrm{s}$. In Table 6 below, comparisons of the critical velocity obtained by this work and by other authors (through numerical and experimental works) are shown.

Table 6. Flutter velocity for the Great Belt East Bridge.

\begin{tabular}{cc}
\hline \multicolumn{2}{c}{ Great Belt East Bridge - Flutter velocity } \\
\hline Reference & $\boldsymbol{V}_{\text {crit }}(\mathbf{m} / \mathbf{s})$ \\
\hline Present work - direct method & 69 \\
\hline Present work - flutter derivative & 73 \\
\hline Selvam et al. (2002) (num.) & $65-72$ \\
\hline Larsen et al. (1997) (num.) & 74 \\
\hline Enevoldsen et al. (1999) (num.) & $70-80$ \\
\hline Wind tunnel tests (from: Larsen et al. (1998)) & 73 \\
\hline
\end{tabular}

\section{Conclusions}

A model for the numerical simulation of the wind action on bridges was described. The computational code was validated through the analysis of a rectangular cross-section and studies of the aerodynamic and aeroelastic behavior of the Great Belt East Bridge cross-section. The results show good agreement with those obtained by other authors. In future works, it is expected to explore other bridge decks, considering details such as cables, guardrails and aerodynamic appendages. It is also expected improvements in the efficiency in processing time, mainly in turbulent flows. An alternative is to use time integration with subcycles (Teixeira \& $A$ rruch $^{\mathrm{a}}, 2$ 2001), optimizing the time step on the computational domain. Another possibility is to use semi-implicit schemes for the flow analysis.

\section{References}

Bathe, K. J. Finite Element Procedures. Prentice Hall, Englewood Cliffs, NJ, 1996.

Braun, A. L. "A Numerical Model for the Simulation of the Wind Action on Bridge Cross-Sections" (In Portuguese), Msc. Thesis, Federal University of Rio Grande do Sul, Porto Alegre, R.S., Brazil, 2002, 139p.

Enevoldsen, I.; Pederson, C.; Hansen, S. O.; Thorbek, L. T. \& Kvamsdal, T. Computational wind simulations for cable-supported bridges. Wind Engineering into the $21^{\text {st }}$ Century, Vol.2, pp. 1265-1270, 1999.

Hirt, C. W.; Amsden, A. A. \& Cook, J. L. An arbitrary LagrangeanEulerian computing method for all flow speeds. Journal of Computational Physics, V.14, pp. 227-253, 1974.

Kawahara, M. \& Hirano, H. A finite element method for high Reynolds number viscous fluid flow using two step explicit scheme. International Journal for Numerical Methods in Fluids, V.3, pp. 137-163, 1983.

Kuroda, S. Numerical simulation of flow around a box girder of a long span suspension bridge. Journal of Wind Engineering and Industrial Aerodynamics, V.67\&68, pp. 239-252, 1997.

Larsen, A. \& Walther, J. H. Aeroelastic analysis of bridge girder sections based on discrete vortex simulation. Journal of Wind Engineering and Industrial Aerodynamics, V.67\&68, pp. 253-265, 1997.

Larsen, A. \& Walther, J. H. Discrete vortex simulation of flow around five generic bridge deck sections. Journal of Wind Engineering and Industrial Aerodynamics, V.77\&78, pp. 591-602, 1998

Rossa, A. L. \& Awruch, A. M. 3-D finite element analysis of incompressible flows with heat transfer. Proceedings of the $2^{\text {nd }}$ International Conference on Computational Heat and Mass Transfer, COPPE/UFRJ,, Rio de Janeiro, Brazil, pp. 22-26, October, 2001.

Reinhold, T. A.; Brinch, M. \& Damsgaard, A. Wind tunnel tests for the Great Belt link. In: Proceedings International Symposium on Aerodynamics of Large Bridge, pp. 255-267, 1992.

Sarrate, J.; Huerta, A. \& Donea, J. Arbitrary Lagrangean-Eulerian formulation for fluid-rigid body interaction. Computer Methods in Applied Mechanics and Engineering, V.190, pp. 3171-3188, 2001.

Scanlan, R. \& Tomko, J. J. Airfoil and bridge deck flutter derivatives. Journal of Engineering Mechanics Division, EM6, pp. 1717-1737, 1971. 
Schlichting, H. Boundary-Layer Theory. McGraw-Hill Inc., New York, $2^{\text {nd }}$ ed., $1978,815 \mathrm{p}$

Selvam, R. P.; Govindaswamy, S. \& Bosch, H. Aeroelastic analysis of bridges using FEM and moving grids. Wind and Structures, V.5, pp. 25-266, 2002 .

Tabarrok, B. \& Su, J. Semi-implicit Taylor-Galerkin finite elemen method for incompressible viscous flows. Computer Methods in Applied Mechanics and Engineering, V.117, pp. 391-410, 1994.

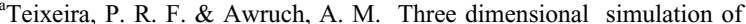
high compressible flows using a multi-time-step integration technique with subcycles. Applied Mathematic Modeling, V.25, pp. 613-627, 2001.

${ }^{6}$ Teixeira, P. R. F. \& Awruch, A. M. Analysis of compressible fluids and elastic structures interaction by the finite element method. Proceedings of the $16^{\text {th }}$ Brazilian Congress of Mechanical Engineering, COBEM 2001, Uberlândia (MG - Brazil), pp. 26-30, November, 2001. 